\title{
Metformin; a review of its history and future: from lilac to longevity
}

\section{Inas Thomas | Brigid Gregg}

Division of Pediatric Endocrinology, Diabetes and Metabolism, Department of Pediatrics and Communicable Diseases, University of Michigan, Ann Arbor, Michigan

\section{Correspondence}

Brigid Gregg, Division of Pediatric

Endocrinology, Diabetes and Metabolism, Department of Pediatrics and Communicable Diseases, University of Michigan, $1500 \mathrm{E}$

Medical Center Drive D1205 MPB, SPC 5718, Ann Arbor, MI 48109.

Email: greggb@med.umich.edu
Metformin is a widely prescribed medication that has been used to treat children with type 2 diabetes in the United States for the past 15 years. Metformin now has a variety of clinical applications in pediatrics, and its potential clinical uses continue to expand. In addition to reviewing the current understanding of its mechanisms of action including the newly discovered effects on the gastrointestinal tract, we will also discuss current clinical uses in pediatrics, including in type 1 diabetes. Finally, we examine the existing state of monitoring for metformin efficacy and side effects and discuss prospective future clinical uses.

\section{KEYWORDS}

diabetes, mechanisms, metformin, pediatrics

\section{1 | INTRODUCTION}

Metformin is an ancient herbal remedy derived from the French lilac that appears in herbal guides dating from the 17th century and described to have properties suitable for treating the symptoms of what we now know to be diabetes. ${ }^{1}$ The specific compound metformin (dimethyl biguanide) was first synthesized in 1922. However, its use was eclipsed by the production of synthetic insulin around the same time. ${ }^{2}$ In the 1950's, the French scientist Jean Sterne published on metformin's properties and named the compound Glucophage, which means glucose eater. From then on, it has been used for the treatment of diabetes. Metformin has found favor for its mild side effect profile, affordability, ease of administration, and positive effects on body weight. Metformin is an oral medication with extended release preparations that allows for once daily dosing. The primary concern is the risk for lactic acidosis in certain patient populations, although this has been estimated to occur at a rate of 9:100 000 patient years. ${ }^{3,4}$ Metformin was approved for use in the United States in 1994. Following the improvement in morbidity and mortality in type 2 diabetes demonstrated in the United Kingdom Prospective Diabetes Study (UKPDS), metformin has been recommended as the first line oral treatment for type 2 diabetes by the American Diabetes Association (ADA) and the European Association for the Study of Diabetes (EASD) since 2009.,6 It is estimated that there are close to 50 million annual prescriptions for metformin in the United States. ${ }^{7}$

\section{I MECHANISM OF ACTION}

Despite the long clinical experience with metformin and active investigation in this area, its exact mechanisms of action remain unclear. In fact, there have been 100 indexed publications on this subject per year since 2008. Metformin is given at large doses relative to other pharmaceuticals, to achieve a therapeutic effect. The therapeutic dose for most patients is in the range of 2 grams per day, suggesting that the effect is not the result of an interaction with a specific protein target. Metformin requires transporters to enter cells and for uptake into the kidney where it is excreted unmetabolized. Polymorphisms in these transporters have been linked to changes in the therapeutic metformin effect in certain patients. Large cohort studies have also indicated polymorphisms in downstream signaling pathways as other mediators of metformin effect. ${ }^{8,9}$

Metformin concentrates in the hepatic circulation. Recent studies have suggested that metformin may have a direct effect on the gastrointestinal mucosa, and the jejeunal concentrations in humans can be up to 300 times that detected in the plasma. ${ }^{2}$ Indeed, gastrointestinal side effects are common but may also be an indicator of therapeutic efficacy. Many of the studies on the mechanism of action of metformin have been performed with concentrations of the drug in in vitro culture that are now thought to be supratherapeutic. However, the concentration that cells are exposed to is tissue dependent with the liver and gastrointestinal tract facing much higher levels of the drug. 


\section{3 | LIVER}

Early studies of the mechanisms of action of metformin used cultured hepatocytes. From these studies metformin was shown to have a specific but mild inhibitory effect on complex 1 of the mitochondrial respiratory chain. ${ }^{10}$ This is thought to change the cellular energy state triggering AMP activated protein kinase (AMPK), a nutrient sensor activated in states of low energy balance. However, some actions of metformin have been found to be AMPK-independent. ${ }^{11}$ Metformin treatment also has beneficial indirect effects that result from lowering circulating glucose and insulin levels.

Metformin was shown to have its predominant effect on lowering blood glucose by decreasing hepatic glucose production in isolated hepatocytes. Later human studies showed a decrease in fasting plasma glucose and gluconeogenesis in patients taking metformin. ${ }^{12}$ Patients with type 2 diabetes have increased hepatic glucose output at baseline, which is then decreased by $75 \%$ in metformin users. ${ }^{13}$ Recent studies have found that metformin decreases hepatic gluconeogenesis via antagonism of the glucagon signaling pathway and also by inhibition of gluconeogenic enzymes in the mitochondria. ${ }^{14,15}$ However, the effects may only be seen at relatively high medication doses. The impact of metformin treatment on circulating glucagon levels in patients with type 2 diabetes is still a matter of debate.

\section{4 | PERIPHERAL INSULIN SENSITIVE TISSUES}

Early animal experiments demonstrated enhanced muscle and liver glucose uptake after dosing with metformin. ${ }^{16}$ In human studies, chronic metformin treatment was shown in hyperinsulinemic euglycemic clamps to increase peripheral glucose uptake. ${ }^{17}$ In in vitro rodent studies it was found to increase insulin-dependent glucose transport into the cell as well as the insulin receptor number and insulin receptor activity. ${ }^{16,18,19}$ It is thought that these actions in the muscle again only occurred at high metformin doses.

\section{5 | GASTROINTESTINAL TRACT}

Metformin's effect on the intestine has also begun to be explored in more detail, as this is a major site of drug concentration. Metformin is thought to play a role in decreasing intestinal glucose uptake. ${ }^{20}$ In addition, metformin has been demonstrated to have an effect on the composition of the intestinal microbiome, which may contribute to its weight lowering effect. In a recent human study by Forslund et al., the specific effect of metformin independent of hyperglycemia was evaluated. In this study the microbiome of patients from 3 cohorts were studied (total $n=784$ ) and the metformin-specific effect included an increase in Escherichia species that was proportional to blood metformin level. ${ }^{21}$ In addition, the microbial community analysis in the metformin-treated patients with type 2 diabetes more closely resembled the control group than the type 2 diabetes group, possibly indicating a rescue from dysbiosis associated with type 2 diabetes.
Incretin hormones from the gut also play a major role in glucose homeostasis. Metformin has been shown to increase postprandial glucagon-like peptide-1 (GLP-1) levels. Metformin has also been shown to increase GLP-1 receptor expression. ${ }^{22}$ It is also thought the increased GLP-1 half-life occurs through a mild decrease in the activity of the degrading enzyme dipeptidyl peptidase 4 (DPP-4); however this mild effect is not likely to make a large contribution to overall circulating active GLP-1 levels. ${ }^{23}$ Finally, metformin treatment has been associated with an increase in gut Escherichia species, and E.coli has been shown to have a direct association with GLP-1 levels. ${ }^{22}$

Much remains to be discovered about the specific mechanism of action of metformin. Understanding these molecular mechanisms may then lead to the design of more specific compounds to achieve metabolic effects while decreasing the possibility of off target effects. A summary of the sites of action of metformin discussed in this review appear in Figure 1.

\section{6 | CLINICAL USES IN PEDIATRICS}

\section{1 | Type 2 diabetes}

Metformin is widely utilized for treatment of type 2 diabetes due to its ability to reduce insulin levels and improve glycemic control. Metformin has been shown to decrease hemoglobin A1c values by $1.3 \%$ $2 \%$, and the degree of reduction is higher in patients with higher pretreatment blood glucose levels. ${ }^{19}$ In a small trial in adolescents, this decrease was $0.7 \%{ }^{24}$ In the UKPDS, the metformin group had improved cardiovascular morbidity and mortality. In addition, the metformin group had better overall health outcomes independent of the degree of lowering of A1c, suggesting additional beneficial effects of metformin. These results lead to the adoption of metformin as the primary agent in both adult and pediatric type 2 diabetes. In terms of patients at risk for type 2 diabetes, the Diabetes Prevention Program (DPP) revealed that lifestyle intervention was as or more effective than using metformin to prevent type 2 diabetes. ${ }^{25,26}$ Metformin did however reduce progression to type 2 diabetes. Metformin is FDA approved for use in patients greater than 10 years of age and the extended release preparation in patients over $17 .^{27}$

\section{2 | Type 1 diabetes}

Recent interest has been generated in using metformin in type 1 diabetes to improve diabetic control as well as manage weight gain in overweight teens. In a pilot study metformin use in type 1 diabetes led to a decrease in insulin dose and improvements in BMI and waist circumference in female participants. ${ }^{28}$ This led to the larger randomized clinical trial conducted by Libman et al. In this study, although metformin appeared to have an effect on decreasing insulin doses and weight gain at 26 weeks, the $\mathrm{HbA1c}$ of the adolescents on metformin was not significantly changed. The authors concluded that addition of metfomrin was not beneficial since the teens also had increased complaints of gastrointestinal distress. ${ }^{29}$ Metformin has shown some potential in preclinical studies to improve diabetic nephropathy, decrease advanced glycation end products (AGE), which 

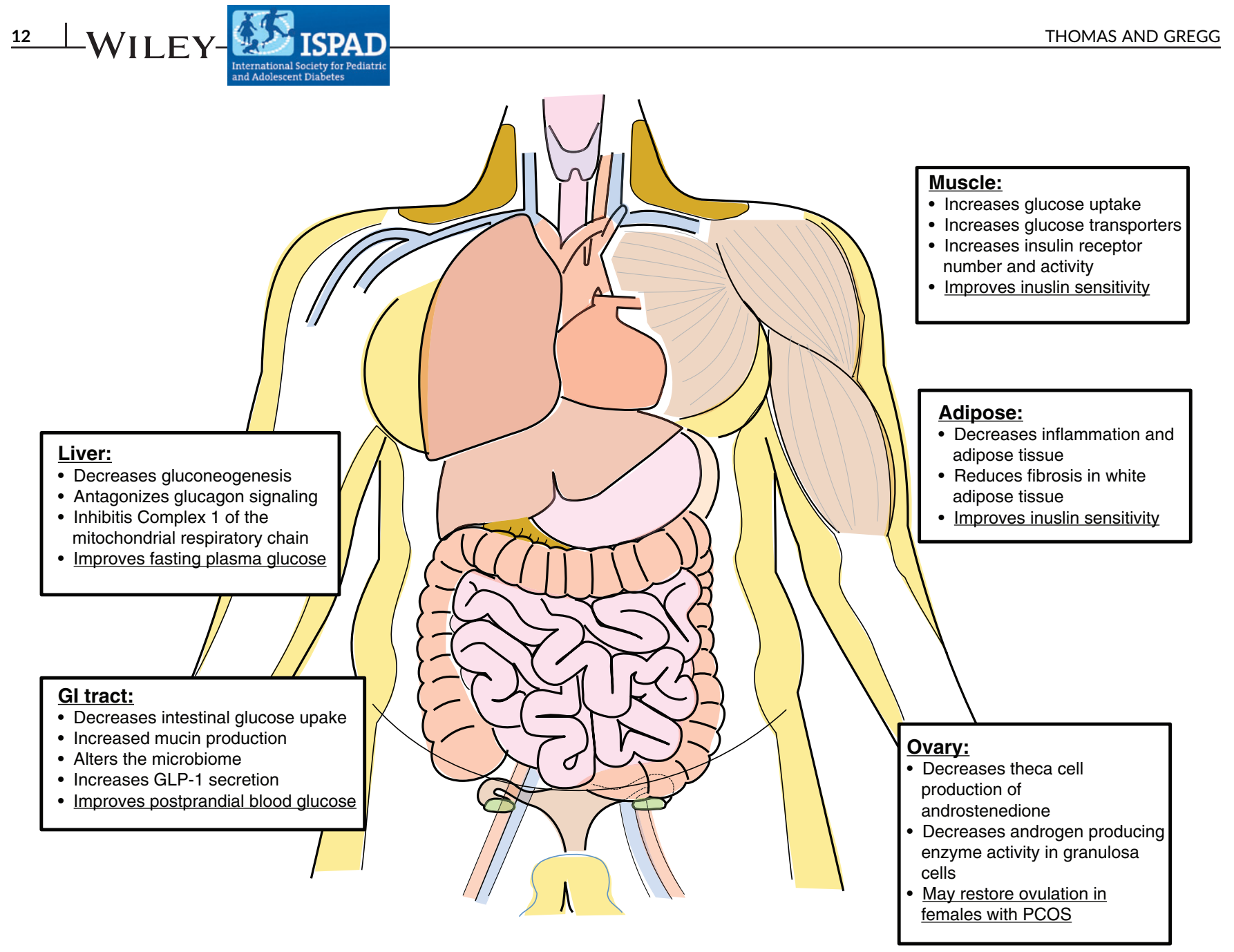

FIGURE 1 A summary of the main sites of metformin action along with the clinical impact on each organ system (underlined).

mediate some diabetic complications, and decrease oxidative stress in endothelial cells. In addition, it has been shown in human clinical studies to improve outcomes in patients with heart failure regardless of lowering of hemoglobin A1c. ${ }^{30}$ Finally, it has shown some benefit in lowering androgen levels in females with type 1 diabetes and hyperandrogenism. ${ }^{31}$ For these reasons, metformin remains a potential treatment in type 1 diabetes and may prove beneficial in longer term studies or specific patient populations.

\section{3 | Obesity}

Metformin has been explored for potential weight loss properties and was shown in a meta-analysis to lead to a mild weight loss of $1.1 \mathrm{~kg}^{32}$ In a separate meta-analysis of trials of overweight and obese adolescents, a combination of metformin and lifestyle changes decreased the body mass index (BMI) by 1.42 as well as the fasting insulin and homeostatic model assessment (HOMA). ${ }^{33}$ Only 1 of the included studies followed the participants for 2 years after the treatment in an attempt to detect a legacy effect and found that the favorable effects on weight subsided after 24 weeks. ${ }^{34}$ Indeed following the DPP there was a smaller study showing 10 year post study outcome. In this study, the metformin group showed continued improvement in weight from initial study baseline; however this effect seems to be driven by participants age 45 and older at randomization. ${ }^{35}$ Metformin has also been shown to be mildly beneficial in weight reduction when added to regimens that include medications that cause weight gain, such as antipsychotic medications. ${ }^{36}$ The inclusion of metformin along with an antipsychotic also had additional benefits as it decreased prolactin levels, which increase with antipsychotic treatment and result in side effects such as menstrual irregularities and galactorrhea. ${ }^{37}$ In studies of children with type 2 diabetes metformin often in combination with lifestyle intervention decreased weight by up to $2.7 \mathrm{~kg}^{24}$ In addition, metformin can supplement exercise to improve left ventricular systolic function in those with insulin resistance. ${ }^{38}$ Metformin has also can been shown to be associated with a mild decrease $\mathrm{n}$ circulating triglyceride levels and LDL cholesterol levels. However in the treatment options for type 2 diabetes in adolescents and youth (TODAY) study these effects were not seen in the metformin alone group. ${ }^{39}$

There was also a recent publication examining the impact of metformin on linear growth in children. This was a meta-analysis of 10 studies in children with a total of over 500 participants. They found that metformin was associated with a small increase in height on the order of $1 \mathrm{~cm}$ in the subgroup that had high dose metformin treatment. ${ }^{40}$ This effect seems driven in large part by a single study using metformin in girls who were had low birthweight and early onset of puberty. The treatment in this group began on average at age 9. Future studies of metformin use in children should include detailed height measurements to better understand this potential effect. 
Finally, a small study was conducted to determine if metformin could prevent adiposity in prepubertal children who were born small for gestational age and had rapid catch up growth. This group of children is typically at increased risk for metabolic diseases in adulthood. ${ }^{41}$ In this study metformin administration at a low dose $(425 \mathrm{mg}$ daily) for 24 months improved abdominal fat as measured by MRI, triglycerides, and insulin resistance as measured by HOMA-IR. ${ }^{42}$

\section{4 | Polycystic ovary syndrome}

Metformin is also used in the treatment of polycystic ovary syndrome (PCOS). It has been shown to have a direct effect on the ovary leading to a decrease in theca cell androstenedione production. It also decreases FSH-stimulated androgen producing enzyme activity in the granulosa cells (3betaHSD, StAR, CYP11a1, and aromatase). Of note, premature pubarche/adrenarche and eventually PCOS are often diagnosed in the same patient, although it is still unclear if those entities share a common pathophysiology. In a small study of children with premature pubarche, treatment with metformin delayed the onset of puberty by 0.4 years and after 4 years of treatment the girls in the study had gained $5.5 \mathrm{~kg}$ less fat than control subjects. ${ }^{43,44}$ They also showed an improvement in androgen levels, insulin resistance and lipids, and these effects persisted 1 year after the treatment was discontinued. ${ }^{45}$ Thus the potential for metformin as a preventative agent in girls at risk of PCOS may exist.

\subsection{Non-alcoholic fatty liver disease}

Metformin has an effect on lipid handling in the hepatocyte, and this has been shown to be via an AMPK-dependent mechanism. ${ }^{20}$ Therefore, metformin is being studied for use in non-alcoholic fatty liver disease (NAFLD) in children. In 1 study there was no benefit of metformin vs lifestyle in improvement of fatty liver disease. However, there was a decrease in the grade of inflammation in the liver upon biopsy with metformin treatment. ${ }^{46}$ Another study found no improvement in NAFLD in metformin vs placebo but they concluded that the dose may have been too low given that there were also no changes in insulin sensitivity, which had been seen in the pilot study. ${ }^{46}$ A subsequent study examined metformin vs vitamin $E$ supplementation and found that metformin can improve liver disease but that it is inferior to vitamin $\mathrm{E}$ treatment when taken long term. The major effect occurred at the 2 month point and was not significant at 4 months. ${ }^{47}$ At this time metformin is not recommended for treatment of NAFLD in children. According to experts in the field, further studies including biopsy specimens need to be done. In adult metaanalyses of studies including liver histology there was also no improvement seen with metformin.

\section{7 | EMERGING USES}

Interest in using metformin as a preventative measure, treatment, or adjuvant drug for cancer has emerged. One study found that in those with diabetes mellitus and gastrointestinal cancers, metformin coupled with a statin appeared to be beneficial in upper gastroinstinal cancers, but not for those with lower gastrointestinal cancers. ${ }^{48}$ There also did not seem to be an effect in those with advanced pancreatic cancers, which led the authors to speculate that it may be a dose-dependent response, which may be blunted in those with advanced cancers. ${ }^{49}$ In terms of the increased risk of cancer in patients with diabetes, it is possible that metformin may decrease this risk. However it does not appear to improve survival time in those patients who do have cancer. Indeed some researchers think the efficacy of metformin as a cancer therapy depends on the molecular pathways that have been altered in the tumor cells. ${ }^{50}$ Additionally, the doses or routes of administration used for diabetes treatment may not be appropriate for cancer chemotherapy. Metformin also decreases the circulating insulin and glucose levels, and these effects may be beneficial in cancer prevention as both are mitogenic factors. Metformin also plays a role in activation of DNA damage repair pathways, which may ultimately protect from the malignant transformation of cells. ${ }^{50}$

\section{I OTHER INDICATIONS THAT HAVE AN IMPACT ON CHILDREN}

Aside from the pediatric uses described above, infants may also receive metformin exposure via maternal metformin use during pregnancy for indications like PCOS, preexisting type 2 diabetes or gestational diabetes. In PCOS, the treatment window begins periconceptionally while with gestational diabetes the treatment usually begins during the second trimester. Studies of metformin use in pregnancy began in the 1970's. While its use remains off-label in pregnancy in the United States, metformin is used during pregnancy more routinely worldwide. A meta-analysis of studies using metformin for gestational diabetes indicated an improvement in macrosomia, infant hypoglycemia, pregnancy induced hypertension, and maternal weight gain. ${ }^{51}$ There are now trials looking at the use of metformin in obese non-diabetic pregnant women and also in the postnatal period to prevent the development of type 2 diabetes after gestational diabetes. Since clinical studies have provided some evidence of a legacy effect remaining in patients after the withdrawal of the medication, it stands to reason that metformin could potentially induce lasting epigenetic changes. Indeed it has been shown to modulate the activity of dicer, a major component of the microRNA processing machinery. ${ }^{52}$ Further studies of offspring of women treated with metformin in pregnancy need to be conducted. A follow-up study of infants born to mothers treated with metformin for gestational diabetes published results at age 2. This showed an increase in subscapular skinfold thickness by calipers but no changes in body composition by dual energy $x$-ray absorptiometry (DXA) in a smaller subset of the children. ${ }^{53}$ The ongoing study is due to publish results on prepubertal offspring soon.

There are preclinical studies in pediatric populations evaluating the possibility of metformin as an intervention after neonatal hypoxemic ischemic brain injury. In this model it was shown to increase the number of neural precursor cells. ${ }^{54}$ There is also a clinical trial underway evaluating the possible use of metformin in combination with another agent in children with Duchenne muscular dystrophy. ${ }^{55} \mathrm{~A}$ summary of current approved uses and potential future applications for metformin appears in Table 1 


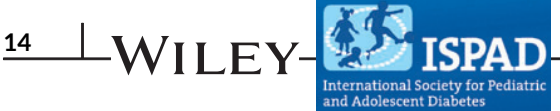

\section{I SIDE EFFECTS AND CONTRAINDICATIONS}

In terms of monitoring during metformin use, there has been a concern about the development of B12 deficiency. This could be consistent with an intestinal site of action of the medication leading to a low-grade malabsorption. However, in the DPP while lower B12 levels were detected, anemia was not. Monitoring also includes following for changes in liver function. In the pediatric studies of metformin there were no reported changes in liver function tests. ${ }^{24}$ Other concerns surround the contraindications for use of metformin. The contraindications for use have been renal impairment, surgery, the use of contrast agents, liver dysfunction, congestive heart failure, alcoholism, metabolic acidosis, dehydration, and hypoxemia. ${ }^{5}$ More recently, however, metformin has shown promise in improving heart failure and NAFLD. In addition, the renal impairment contraindication has been debated and laxened, given the very rare occurrence of lactic acidosis that was not proven to have a causal link to metformin in a Cochrane database review. ${ }^{5,56} \mathrm{~A}$ recent case series was published suggesting a link between metformin use and early onset lung cancer. ${ }^{57}$ Follow-up from this publication will be important since this has not previously been reported after many patient years of treatment experience with this medication.

\section{0 | FUTURE PERSPECTIVES}

Metformin is considered first line treatment in type 2 diabetes, but when adequate glycemic control is not achieved, combination therapy is recommended. Several pharmaceutical manufacturers have released combination agents for use in type 2 diabetes. In addition to starting insulin, there are 14 combination pills which include metformin with another oral agent that can be used in individuals greater than 18 years old. Often these combination agents use other medications that can also be used independently to treat type 2 diabetes including Glyburide (sulfonylurea), Canagliflozin (sodium-glucose cotransporter 2 (SGLT2) inhibitor), and Alogliptin (dipeptidyl peptidase4 (DPP-4) inhibitor). ${ }^{58}$ To date there are no published trials of the use of these combination agents in the pediatric population.

TABLE 1 Approved and potential uses of metformin in pediatrics

\begin{tabular}{|c|c|}
\hline Approved & Potential \\
\hline Type 2 diabetes & Type 1 diabetes \\
\hline $\begin{array}{l}\text { Obesity (in conjunction with } \\
\text { lifestyle intervention) }\end{array}$ & Cancer (solid tumors and leukemia) \\
\hline \multirow[t]{6}{*}{ PCOS } & Weight gain with antipsychotic use \\
\hline & $\begin{array}{l}\text { Pancreatic beta-cell rest in new } \\
\text { onset type } 2 \text { diabetes }\end{array}$ \\
\hline & $\begin{array}{l}\text { Brain injury due to stroke or } \\
\text { radiation therapy }\end{array}$ \\
\hline & Duchenne muscular dystrophy \\
\hline & $\begin{array}{l}\text { Gestational diabetes (fetal } \\
\text { exposure) }\end{array}$ \\
\hline & $\begin{array}{l}\text { Lactation failure (newborn } \\
\text { exposure) }\end{array}$ \\
\hline
\end{tabular}

PCOS, polycystic ovary syndrome.
Newer preparations are also being designed to deposit metformin in different mucosal locations to either enhance current beneficial effects or try to improve efficacy in cancer treatment by delivering a higher dose but avoiding side effects that typically cause discontinuation. ${ }^{59}$ One preparation is made to deliver metformin to the distal small bowel, as there is a thought that this may be the main site mediating the effect of the medication. Such localized delivery would theoretically avoid other systemic sites of action. In addition, other dosing strategies that allow for direct contact with mucosal surfaces being developed include direct bladder lavage after a recent study showed efficacy in a preclinical model of bladder cancer. ${ }^{60}$ There is also a clinical trial using a vaginal preparation to treat PCOS while minimizing size effects in an effort to improve tolerability. A recent publication also announced a new metformin polymer that can deliver metformin plus a siRNA species for chemotherapy.

In order for our understanding of the mechanisms of action of metformin to improve, we must understand the concentrations achieved in specific target tissues and then be certain to use these physiologically relevant concentrations in future mechanistic studies. In addition, many studies also employ an acute exposure timeline, which may not be relevant to the chronic clinical use of the medication. Another complicating matter for studies of metformin is that the effect seems to differ depending on the metabolic and nutrient status of the recipient. In experimental systems it seems to have an enhanced effect in states of hyperglycemia and in the setting of high fat diet. In clinical studies metformin may have beneficial effects on cardiovascular mortality in only diabetic patients. ${ }^{20}$ In the DPP participants who were younger, weighed more and were women with a history of gestational diabetes, those individuals had better treatment efficacy. ${ }^{61}$

At present the use of measured metformin levels is generally restricted to determining if cases represent toxicity. Even the therapeutic window for metformin effect is not agreed upon. We should consider routinely measuring metformin levels in clinical studies in order to understand the correlation between metformin dose and clinical outcome. Gaining an understanding of the levels achieved in patients who demonstrate a clinical benefit will allow for more accurate study of metformin actions. A recent clinical study has also described a potential circulating biomarker of metformin action in the liver. ${ }^{62}$ It will be interesting to see how this biomarker contributes to our understanding of metformin activity on an individual level.

Metformin is a well-tolerated medication that has efficacy in a variety of clinical conditions and has a low risk of toxicity when used according to guidelines. However, the effect of metformin alone is mild in most of the conditions described and often fails to achieve goal therapeutic endpoints without the addition of another medication. Additionally, the mechanisms of metformin's effects still remain mysterious, leaving the possibility of unforeseen consequences, which may now come to attention with widespread use. Despite these drawbacks, metformin is widely used and its potential clinical applications continue to expand (Table 1). Indeed, it is now being studied as a treatment to promote longevity suggesting that the future horizons for this ancient compound are broad. 


\section{ACKNOWLEDGMENTS}

We would like to thank Greg Thomas for his assistance with the illustration for this manuscript. We would also like to thank David Olson for helping to edit the manuscript.

\section{REFERENCES}

1. Bailey CJ, Day C. Traditional plant medicines as treatments for diabetes. Diabetes Care. 1989;12(8):553-564.

2. Pryor R, Cabreiro F. Repurposing metformin: an old drug with new tricks in its binding pockets. Biochem J. 2015;471(3):307-322.

3. Howlett HC, Bailey CJ. A risk-benefit assessment of metformin in type 2 diabetes mellitus. Drug Saf. 1999;20(6):489-503.

4. Stang M, Wysowski DK, Butler-Jones D. Incidence of lactic acidosis in metformin users. Diabetes Care. 1999;22(6):925-927.

5. Inzucchi SE. Oral antihyperglycemic therapy for type 2 diabetes: scientific review. JAMA. 2002;287(3):360-372.

6. Nathan DM, Buse JB, Davidson MB, et al. Medical management of hyperglycemia in type 2 diabetes: a consensus algorithm for the initiation and adjustment of therapy: a consensus statement of the American Diabetes Association and the European Association for the Study of Diabetes. Diabetes Care. 2009;32(1):193-203.

7. IMS Institute for Healthcare Informatics. The Use of Medicines in the United States: Review of 2010. IMS Health.com. Accessed June 10, 2016.

8. Todd JN, Florez JC. An update on the pharmacogenomics of metformin: progress, problems and potential. Pharmacogenomics. 2014;15(4):529-539.

9. Pawlyk AC, Giacomini KM, McKeon C, Shuldiner AR, Florez JC. Metformin pharmacogenomics: current status and future directions. Diabetes. 2014;63(8):2590-2599.

10. El-Mir MY, Nogueira V, Fontaine E, Averet N, Rigoulet M, Leverve X. Dimethylbiguanide inhibits cell respiration via an indirect effect targeted on the respiratory chain complex I. J Biol Chem. 2000;275(1):223-228.

11. Miller RA, Birnbaum MJ. An energetic tale of AMPK-independent effects of metformin. J Clin Invest. 2010;120(7):2267-2270.

12. Perriello G, Misericordia P, Volpi E, et al. Acute antihyperglycemic mechanisms of metformin in NIDDM. Evidence for suppression of lipid oxidation and hepatic glucose production. Diabetes. 1994;43(7):920-928.

13. Stumvoll M, Nurjhan N, Perriello G, Dailey G, Gerich JE. Metabolic effects of metformin in non-insulin-dependent diabetes mellitus. N Engl J Med. 1995;333(9):550-554.

14. Miller RA, Chu Q, Xie J, Foretz M, Viollet B, Birnbaum MJ. Biguanides suppress hepatic glucagon signalling by decreasing production of cyclic AMP. Nature. 2013;494(7436):256-260.

15. Madiraju AK, Erion DM, Rahimi $Y$, et al. Metformin suppresses gluconeogenesis by inhibiting mitochondrial glycerophosphate dehydrogenase. Nature. 2014;510(7506):542-546.

16. Bailey CJ, Puah JA. Effect of metformin on glucose metabolism in mouse soleus muscle. Diabete Metab. 1986;12(4):212-218.

17. Musi N, Hirshman MF, Nygren J, et al. Metformin increases AMPactivated protein kinase activity in skeletal muscle of subjects with type 2 diabetes. Diabetes. 2002;51(7):2074-2081.

18. Rossetti L, DeFronzo RA, Gherzi R, et al. Effect of metformin treatment on insulin action in diabetic rats: in vivo and in vitro correlations. Metabolism. 1990;39(4):425-435.

19. Kirpichnikov D, McFarlane SI, Sowers JR. Metformin: an update. Ann Intern Med. 2002;137(1):25-33.

20. Foretz M, Guigas B, Bertrand L, Pollak M, Viollet B. Metformin: from mechanisms of action to therapies. Cell Metab. 2014;20(6):953-966.

21. Forslund K, Hildebrand F, Nielsen T, et al. Disentangling type 2 diabetes and metformin treatment signatures in the human gut microbiota. Nature. 2015;528(7581):262-266.

22. Maida A, Lamont BJ, Cao X, Drucker DJ. Metformin regulates the incretin receptor axis via a pathway dependent on peroxisome proliferator-activated receptor-alpha in mice. Diabetologia. 2011:54(2):339-349.
23. Bahne E, Hansen M, Bronden A, Sonne DP, Vilsboll T, Knop FK. Involvement of glucagon-like peptide- 1 in the glucose-lowering effect of metformin. Diabetes Obes Metab. 2016;18:955-961.

24. Brufani C, Fintini D, Nobili V, Patera PI, Cappa M, Brufani M. Use of metformin in pediatric age. Pediatr Diabetes. 2011;12(6):580-588.

25. Diabetes Prevention Program Research Group. Long-term effects of lifestyle intervention or metformin on diabetes development and microvascular complications over 15-year follow-up: the Diabetes Prevention Program Outcomes Study. Lancet Diabetes Endocrinol. 2015;3(11):866-875.

26. Knowler WC, Barrett-Connor E, Fowler SE, et al. Reduction in the incidence of type 2 diabetes with lifestyle intervention or metformin. N Engl J Med. 2002;346(6):393-403.

27. Product Information: GLUCOPHAGE(R), GLUCOPHAGE(R)XR oral tablets, extended-release oral tablets, metformin hydrochloride oral tablets, extended-release oral tablets. Bristol-Myers Squibb Company, Princeton, NJ2009

28. Nadeau KJ, Chow K, Alam S, et al. Effects of low dose metformin in adolescents with type I diabetes mellitus: a randomized, doubleblinded placebo-controlled study. Pediatr Diabetes. 2015;16(3):196-203.

29. Libman IM, Miller KM, DiMeglio LA, et al. Effect of metformin added to insulin on glycemic control among overweight/obese adolescents with type 1 diabetes: a randomized clinical trial. JAMA. 2015;314(21):2241-2250.

30. Evans JM, Doney AS, AlZadjali MA, et al. Effect of Metformin on mortality in patients with heart failure and type 2 diabetes mellitus. Am J Cardiol. 2010;106(7):1006-1010.

31. Bacha F, Klinepeter Bartz S. Insulin resistance, role of metformin and other non-insulin therapies in pediatric type 1 diabetes. Pediatr Diabetes. 2015;17:545-558.

32. Domecq JP, Prutsky G, Leppin A, et al. Clinical review: drugs commonly associated with weight change: a systematic review and metaanalysis. J Clin Endocrinol Metab. 2015;100(2):363-370.

33. Bouza C, Lopez-Cuadrado T, Gutierrez-Torres LF, Amate J. Efficacy and safety of metformin for treatment of overweight and obesity in adolescents: an updated systematic review and meta-analysis. Obes Facts. 2012;5(5):753-765.

34. Wilson DM, Abrams SH, Aye T, et al. Metformin extended release treatment of adolescent obesity: a 48-week randomized, doubleblind, placebo-controlled trial with 48-week follow-up. Arch Pediatr Adolesc Med. 2010;164(2):116-123.

35. Knowler WC, Fowler SE, Hamman RF, et al. 10-year follow-up of diabetes incidence and weight loss in the Diabetes Prevention Program Outcomes Study. Lancet. 2009;374:1677-1186.

36. Generali JA, Cada DJ. Metformin: prevention and treatment of antipsychotic-induced weight gain. Hosp Pharm. 2013;48(9):734-777.

37. Bo QJ, Wang ZM, Li XB, Ma X, Wang CY, de Leon J. Adjunctive metformin for antipsychotic-induced hyperprolactinemia: a systematic review. Psychiatry Res. 2016;237:257-263.

38. Cadeddu C, Nocco S, Cugusi L, et al. Effects of metformin and exercise training, alone or in combination, on cardiac function in individuals with insulin resistance. Cardiol Ther. 2016;5:63-73.

39. TODAY Study Group. Lipid and inflammatory cardiovascular risk worsens over 3 years in youth with type 2 diabetes: the TODAY clinical trial. Diabetes Care. 2013;36(6):1758-1764.

40. Kuzik N, Myette-Cote E, Carson V, Slater L, Boule NG. Evaluating the effects of metformin use on height in children and adolescents: a meta-analysis of randomized clinical trials. JAMA Pediatr. 2015;169(11):1032-1039.

41. Stroescu R, Micle I, Bizerea T, Puiu M, Marginean O, Doros G. Metabolic monitoring of obese children born small for gestational age. Obes Res Clin Pract. 2014;8(6):e592-e598.

42. Diaz M, Bassols J, Lopez-Bermejo A, de Zegher F, Ibanez L. Metformin treatment to reduce central adiposity after prenatal growth restraint: a placebo-controlled pilot study in prepubertal children. Pediatr Diabetes. 2015;16(7):538-545.

43. Ibanez L, Lopez-Bermejo A, Diaz M, Marcos MV, de Zegher F. Metformin treatment for four years to reduce total and visceral fat in low birth weight girls with precocious pubarche. J Clin Endocrinol Metab. 2008;93(5):1841-1845, DOI: 10.1210/jc.2008-0013. 
44. Ibanez L, Ong K, Valls C, Marcos MV, Dunger DB, de Zegher F. Metformin treatment to prevent early puberty in girls with precocious pubarche. J Clin Endocrinol Metab. 2006;91(8):2888-2891.

45. Ibanez L, Lopez-Bermejo A, Diaz M, Marcos MV, de Zegher F. Pubertal metformin therapy to reduce total, visceral, and hepatic adiposity. J Pediatr. 2010;156(1):98-102.

46. Lavine JE, Schwimmer JB, Van Natta ML, et al. Effect of vitamin E or metformin for treatment of nonalcoholic fatty liver disease in children and adolescents: the TONIC randomized controlled trial. JAMA. 2011;305(16):1659-1668.

47. Shiasi Arani K, Taghavi Ardakani A, Moazami Goudarzi R, et al. Effect of vitamin $E$ and metformin on fatty liver disease in obese children- randomized clinical trial. Iran J Public Health. 2014;43(10):1417-1423.

48. Nimako GK, Wintrob ZA, Sulik DA, Donato JL, Ceacareanu AC. Synergistic benefit of statin and metformin in gastrointestinal malignancies. J Pharm Pract. 2016. pii: 0897190015627255

49. Kordes S, Pollak MN, Zwinderman $\mathrm{AH}$, et al. Metformin in patients with advanced pancreatic cancer: a double-blind, randomised, placebo-controlled phase 2 trial. Lancet Oncol. 2015;16(7):839-847.

50. Pernicova I, Korbonits M. Metformin--mode of action and clinical implications for diabetes and cancer. Nat Rev Endocrinol. 2014;10(3):143-156.

51. Butalia S, Gutierrez L, Lodha A, Aitken E, Zakariasen A, Donovan L. Short- and long-term outcomes of metformin compared with insulin alone in pregnancy: a systematic review and meta-analysis. Diabet Med. 2016. DOI: 10.1111/dme.13150

52. Blandino $G$, Valerio $M$, Cioce $M$, et al. Metformin elicits anticancer effects through the sequential modulation of DICER and c-MYC. Nat Commun. 2012;3:865.

53. Rowan JA, Rush EC, Obolonkin V, Battin M, Wouldes T, Hague WM. Metformin in gestational diabetes: the offspring follow-up (MiG TOFU): body composition at 2 years of age. Diabetes Care. 2011;34(10):2279-2284.

54. Dadwal P, Mahmud N, Sinai L, et al. Activating endogenous neural precursor cells using metformin leads to neural repair and functional recovery in a model of childhood brain injury. Stem Cell Reports. 2015;5(2):166-173.

55. Hafner $\mathrm{P}$, Bonati $U$, Rubino $\mathrm{D}$, et al. Treatment with L-citrulline and metformin in Duchenne muscular dystrophy: study protocol for a single-centre, randomised, placebo-controlled trial. Trials. 2016;17(1):389.

56. FDA Drug Safety Communication: FDA revises warnings regarding use of the diabetes medicine metformin in certain patients with reduced kidney function. http://www.fda.gov/Drugs/DrugSafety/ ucm493244.htm. Accessed June 10, 2016.

57. Sakoda LC, Ferrara A, Achacoso NS, et al. Metformin use and lung cancer risk in patients with diabetes. Cancer Prev Res (Phila). 2015;8(2):174-179.

58. Lexicomp Online [database on the Internet]. Wolters Kluwer. Accessed: August 14, 2016.

59. DeFronzo RA, Buse JB, Kim T, et al. Once-daily delayed-release metformin lowers plasma glucose and enhances fasting and postprandial GLP-1 and PYY: results from two randomised trials. Diabetologia. 2016;59:1645-54.

60. Abdemur A, Han SM, Lo Menzo E, Szomstein S, Rosenthal R. Reasons and outcomes of conversion of laparoscopic sleeve gastrectomy to Roux-en-Y gastric bypass for nonresponders. Surg Obes Relat Dis. 2016;12(1):113-118.

61. Srinivasan S, Florez JC. Therapeutic challenges in diabetes prevention: we have not found the "exercise pill". Clin Pharmacol Ther. 2015;98(2):162-169.

62. He L, Meng S, Germain-Lee EL, Radovick S, Wondisford FE. Potential biomarker of metformin action. J Endocrinol. 2014;221(3):363-369.

How to cite this article: Thomas I, Gregg B. Metformin; a review of its history and future: from lilac to longevity, Pediatr Diabetes, 2017;18(1):10-16. 